\title{
Zwietering's Equation for the Suspension of Porous Particles and the Use of Curved Blade Impellers
}

\author{
S. Ibrahim, S. N. Jasnin, S. D. Wong, and I. F. Baker \\ Department of Civil Engineering, Faculty of Engineering, University of Malaya, 50603 Kuala Lumpur, Malaysia \\ Correspondence should be addressed to S. Ibrahim, shaliza@um.edu.my
}

Received 13 January 2012; Revised 17 March 2012; Accepted 22 March 2012

Academic Editor: Shunsuke Hashimoto

Copyright () 2012 S. Ibrahim et al. This is an open access article distributed under the Creative Commons Attribution License, which permits unrestricted use, distribution, and reproduction in any medium, provided the original work is properly cited.

The minimum speed for just-suspension, $N_{\mathrm{j} s}$, of porous palm shell-activated carbon (PSAC) particles has been determined in a $15 \mathrm{~cm}$ diameter cylindrical tank using a 6-curved blade (6CB) impeller, compared to a 6-blade downpumping mixed-flow (6MFD) impeller and a Rushton turbine (6DT). The particles size ranged from $0.75-1.00 \mathrm{~mm}, 1.00-1.40 \mathrm{~mm}$, and $1.40-2.36 \mathrm{~mm}$ with concentrations between 0 and $5 \%$ by weight. The $6 \mathrm{CB}$ being a radial impeller performed similarly to 6DT in terms of speed and power requirement at just-suspension, and particles distribution on the base. The 6MFD, with power requirement $100 \%$ to $200 \%$ less than the radial impellers, was the most efficient for suspending the particles, as usually reported for the range of solid concentrations used here. Specific power per unit mass for all three impellers showed reduction towards minima as the concentration of particles increased. The geometric factor, $S$, values agreed reasonably with published data, when the particle density was adjusted taking into account water filling the pores of the submerged activated carbon. This result means that Zwietering's equation can be used to predict suspension for porous particles with adjustment to the particle density. $S$ values for curved-blade impellers are presented for the first time.

\section{Introduction}

The suspension of solid particles in liquid in a stirred tank occurs in a wide variety of processes from crystallization to ore processing $[1,2]$. Downpumping mixed or axial impellers have been reported to be the most efficient geometries for suspending solids, while radial impellers require substantially higher power to achieve suspension $[3,4]$. Radial impellers are, however, still relevant in solid-liquid mixing since this impeller geometry is efficient for gas-liquid dispersion, and many such systems also contain solids [5-9] such as in aerobic fermentation and activated sludge treatment. The curved blade impeller has gained popularity as an alternative to the Rushton due to its efficiency in gas-liquid dispersion as the shape of the curve eliminates or minimizes the formation of cavities that lead to substantial drop in power. There is few reported work, if any, on the use of curved blade impellers for particle suspension.

In solid suspension studies, the particles used are usually fully solid, where the density is simply the particle density [10-21]. The use of porous particles is not commonly reported, although porous particles are relevant in processes such as adsorption. Adsorption processes are usually carried out in columns; nevertheless, it is also of interest to study the suspension of these particles in the stirred tank as this would be a potential configuration for application in water or wastewater treatment and similar processes. When porous particles are submerged in a fluid, the fluid will gradually fill the pores of the particle, and the particle density would have to incorporate the fluid density by a factor of the pore percentage. If Zwietering's [22] correlation is to be used to predict $N_{\text {js }}$ for the porous particles, using the adjusted density value for the particles would be more appropriate.

The objective of this paper is to assess the solidsuspension ability of the curved blade impeller and the use of Zwietering's equation to predict just-suspension of porous particles.

\section{Materials and Methods}

The experiments were conducted in a $0.15 \mathrm{~m}$ diameter $(T)$ cylindrical-baffled (standard) vessel filled with distilled water 


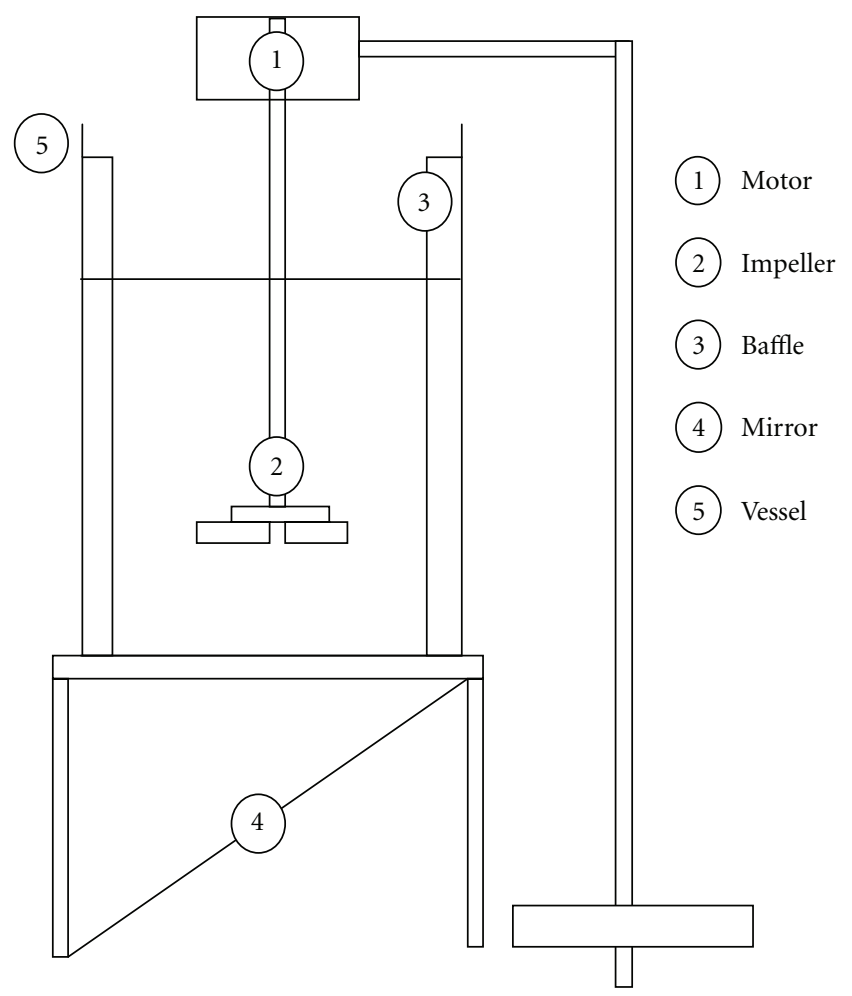

FIGURE 1: Schematic of experimental setup of motor, agitator, tank, and mirror.

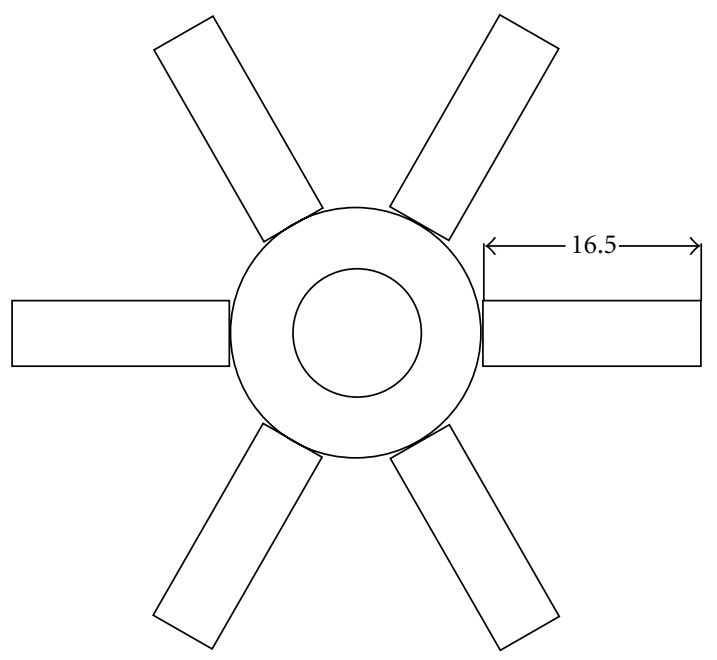

(a) $6 \mathrm{CB}$ (top)

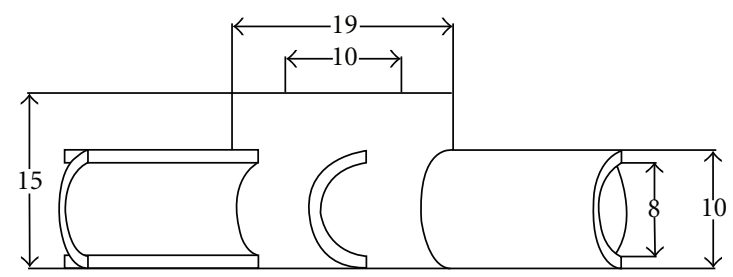

(b) $6 \mathrm{CB}$ (side)

Figure 2: 6CB.

to a height equal to the diameter, giving a volume of $2.65 \mathrm{~L}$. Figure 1 shows a schematic of the setup. Three types of impellers used were 6-blade mixed flow pumping downward (6MFD), the 6-blade Rushton turbine (6DT), and a 6-curved blade turbine (6CB). Schematic diagrams of the impellers are provided by Figures 2, 3, and 4. The curved blade used in this work does not have a central disc as does the Rushton turbine.
The experiments were performed at a constant liquid depth $(H=T)$ and with a constant impeller clearance $(C=$ $T / 4)$. An impeller diameter of $5 \pm 0.1 \mathrm{~cm}$ gives a $D / T$ ratio of about $1 / 3$. The impeller is mounted on a shaft connected to a motor that displays speed and torque readings. The speed can be set from $0 \mathrm{rpm}$ to $2000 \mathrm{rpm}$. The power of agitation is calculated based on the difference between torque reading during impeller rotation in air and rotation in the actual 


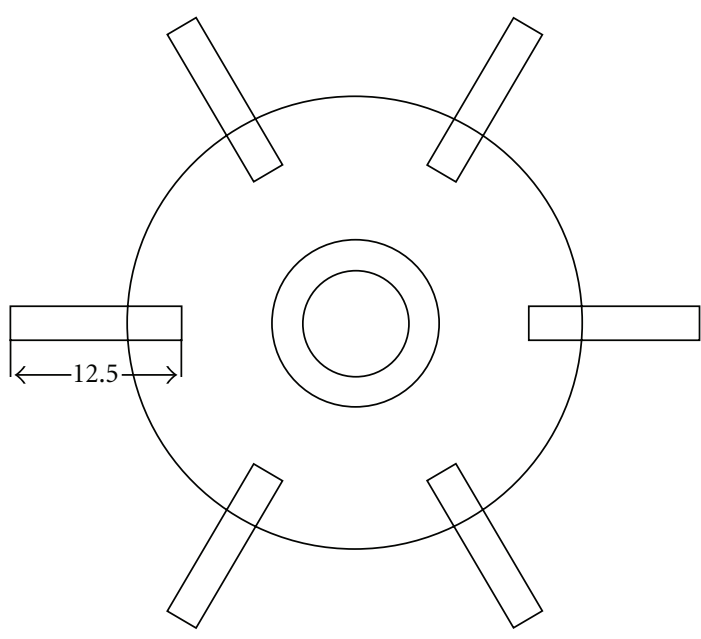

(a) 6DT (top)

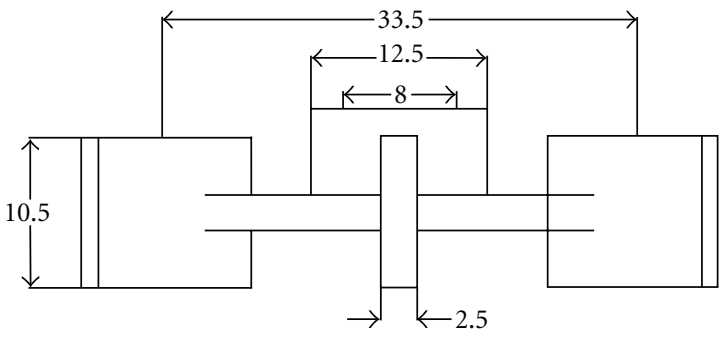

(b) 6DT (side)

FIgURE 3: 6DT.

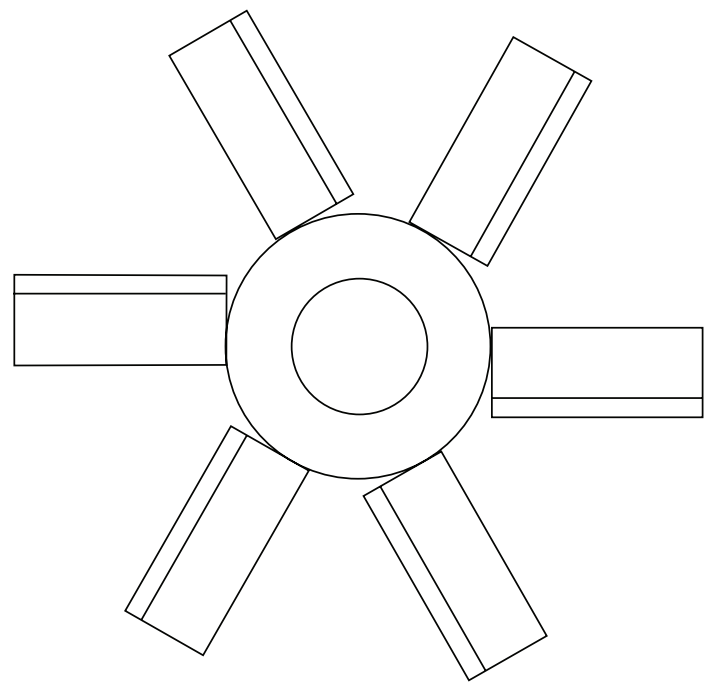

(a) 6MFD (top)

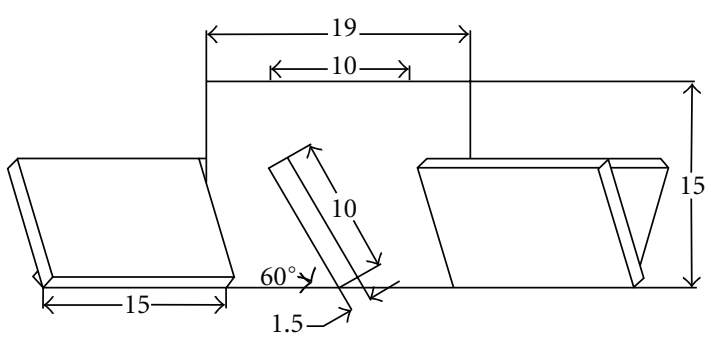

(b) $6 \mathrm{MFD}$ (side)

Figure 4: 6MFD.

fluid. Before experimental runs, the motor was warmed up for at least 20 minutes.

Palm shell-activated carbon (PSAC) was used as the porous solids to be suspended. The properties of the particles are given in Table 1 based on a sample of the particles. The assumption made in this work is that the same characteristics apply for all the size ranges. The particles were segregated by sieving according to the size range: $0.75-1.00 \mathrm{~mm}, 1.00$ $1.40 \mathrm{~mm}$, and $1.40-2.36 \mathrm{~mm}$. Any superficial impurities were cleaned to ensure that no other substances were included in the experiments.

The PSAC solid density has been determined to be $1700 \mathrm{~kg} / \mathrm{m}^{3}$. This is higher than water density, and the particles were observed to readily sink in the tank as soon as they were poured into the water. However, particle density value in Zwietering's equation should incorporate the fact
TABLE 1: Results of BET test for PSAC particles.

\begin{tabular}{lc}
\hline Parameter (unit) & Value \\
\hline BET surface area $\left(\mathrm{m}^{2} / \mathrm{g}\right)$ & 941 \\
Micropore area $\left(\mathrm{m}^{2} / \mathrm{g}\right)$ & 764 \\
Average pore diameter $(\mathrm{nm})$ & 2.213 \\
Pore volume $\left(\mathrm{cm}^{3} / \mathrm{g}\right)$ & 0.524 \\
Micropore volume $\left(\mathrm{cm}^{3} / \mathrm{g}\right)$ & 0.496 \\
\hline
\end{tabular}

that the activated carbon pores are filled with water once they are submerged. It is necessary to consider this fluid-filled pores, when it concerns the lifting or suspension of these 


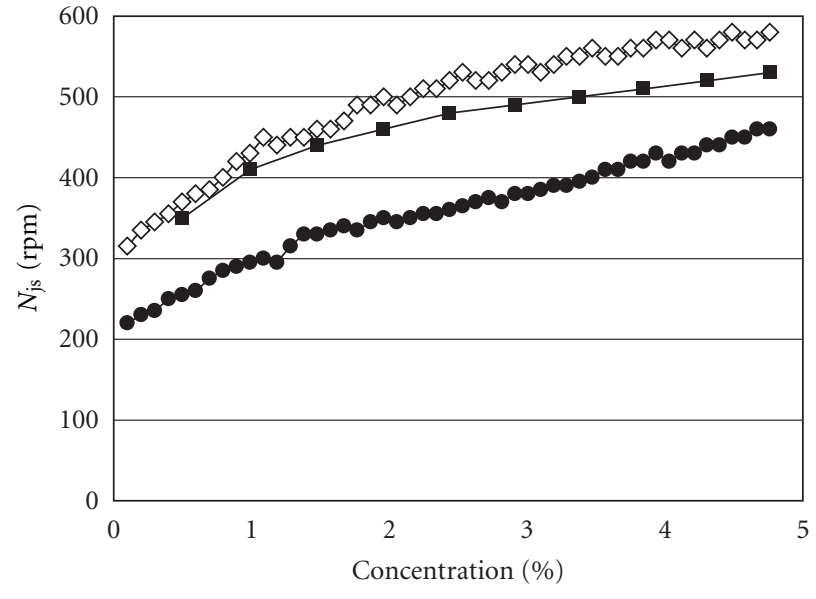

(a)

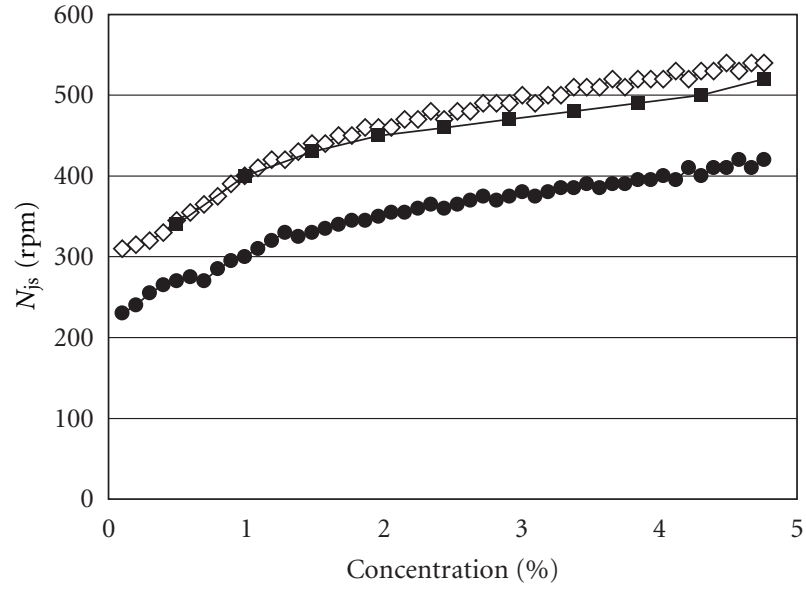

(b)

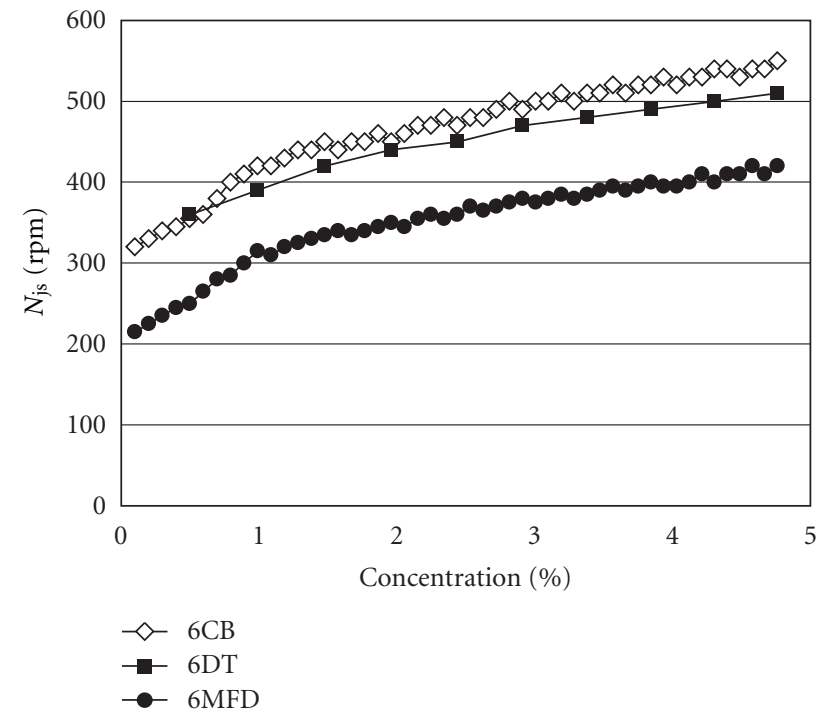

(c)

FIGURE 5: $N_{\mathrm{js}}(\mathrm{rpm})$ versus concentration (\%), at varying impeller geometries. (a) size of activated carbon: 1.40-2.36 mm, (b) size of activated carbon: $1.00-1.40 \mathrm{~mm}$, (c) size of activated carbon: $0.75-1.00 \mathrm{~mm}$.

particles in water. This effective density of the submerged particle can be calculated as follows:

$$
\begin{aligned}
\rho_{s, \mathrm{eff}} & =(1-\varepsilon) \rho_{s}+\varepsilon \rho_{L} \\
& =(1-0.524) \times 1700+(0.524 \times 1000) \\
& =1333.2 \mathrm{~kg} \mathrm{~m}^{-3} .
\end{aligned}
$$

The effective density is used in Zwietering's equation.

The concentrations of activated carbon (solids) ranged from 0.0 to $4.8 \%$ by weight, with $0.1 \%$ increments for $6 \mathrm{CB}$ and $6 \mathrm{MFD}$, and $0.5 \%$ increments for $6 \mathrm{DT}$. Since the solids volume is relatively low, the total water volume is assumed constant at 2.65L throughout the experiments Solids mass, $x$, was calculated based on solids-to-liquid ratio. As an example:
$0.5 \mathrm{~g}$ PSAC $/ 100 \mathrm{~g}$ water $=5 \mathrm{~g}$ PSAC $/ \mathrm{kg}$ water $=5 \mathrm{~g}$ PSAC/liter water,

$5 \mathrm{~g}$ PSAC/liter water $\times 2.65$ liter $=13.25 \mathrm{~g}$ PSAC $=x$.

An increment of " $0.1 \%$ " means an additional $0.1 \mathrm{~g}$ PSAC/ $100 \mathrm{~g}$ water $=1 \mathrm{~g}$ PSAC $/ \mathrm{kg}$ water $=1 \mathrm{~g}$ PSAC/liter water, hence $2.65 \mathrm{~g}$ of PSAC for each increment. There are 50 experimental points each for $6 \mathrm{MFD}$ and $6 \mathrm{CB}$ at every particle size range, while the Rushton had 10 experimental points for every particle size range. $N_{\mathrm{js}}$ was determined visually for each concentration of particles and experimental condition.

In using Zwietering's equation to calculate $S$ values, the solids concentration $(X)$ is given as:

$$
X(\%)=\frac{x}{x+\text { water mass }} \times 100 \%=\frac{x}{x+2.65 \mathrm{~kg}} \times 100 \% \text {, }
$$

where $x$ is mass of solids in $\mathrm{kg}$. 


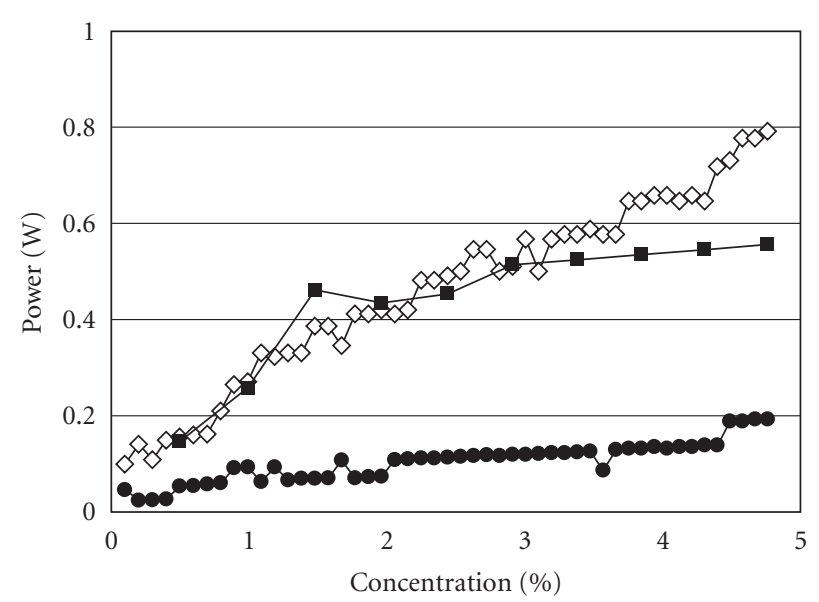

(a)

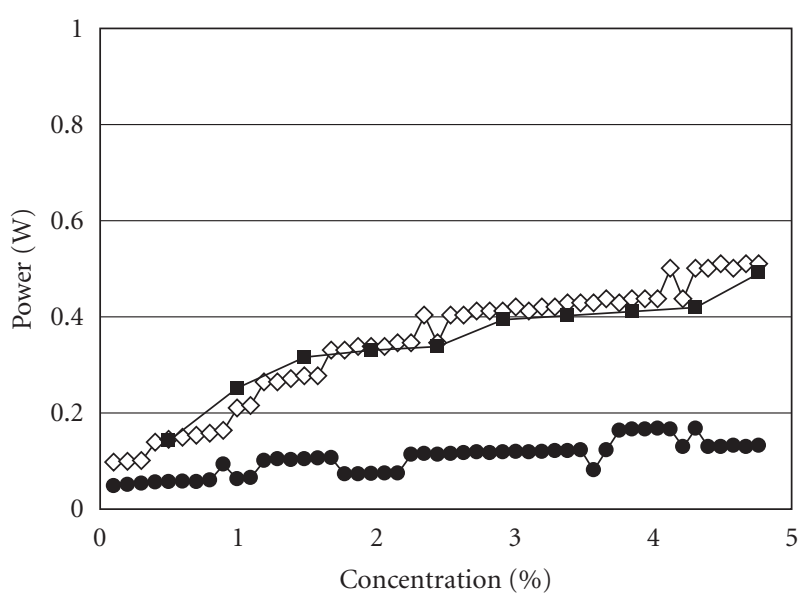

(b)

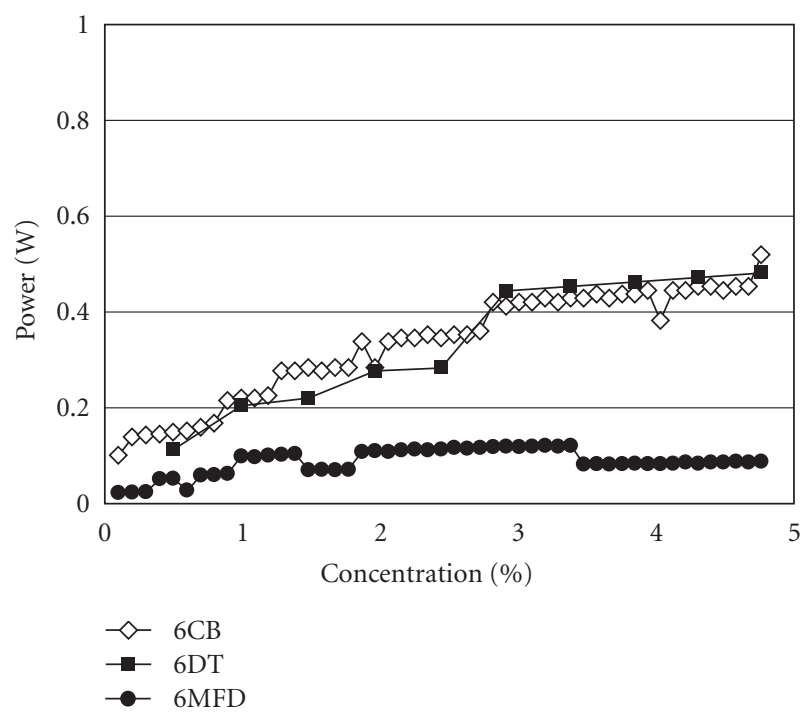

(c)

Figure 6: Power (watt) versus concentration (\%), at varying impeller geometries. (a) size of activated carbon 1.40-2.36 mm. (b) size of activated carbon $1.00-1.40 \mathrm{~mm}$. (c) size of activated carbon $0.75-1.00 \mathrm{~mm}$.

2.1. Determining the $N_{j s}$. The minimum speed for just suspension, $N_{\text {js }}$ was ascertained by increasing the motor speed ranging from $0 \mathrm{rpm}$ until complete suspension is deemed achieved based on the 1-2 s Zwietering criteria. The suspension of particles was observed with the naked eye, aided by a mirror located at an angle below the vessel and a halogen lamp shone from the side. Particle distribution with each impeller was observed and recorded. It was not easy to view the particles due to the black color of the solids rendering the whole tank completely dark. Nevertheless, it was still possible to distinguish the individual particles on the base for all the concentrations studied here. The use of a lamp was helpful to a certain extent.

2.2. Power Consumption. The torque value displayed on the motor screen was recorded once the minimum speed for complete suspension was determined. At that speed of $N_{\mathrm{j} s}$, torque readings were later taken again with the impeller rotating in air. This gives a baseline reading which is subtracted from the earlier value obtained in the solid-liquid mixture, to give the actual net torque for agitation at $N_{\text {js }}$ during just-suspension. In other words, the actual torque value for the impeller at $N_{\mathrm{js}}$ is obtained by deducting the torque value in the liquid-solid mixture with the torque value in air. Then, the data is put into the equation below for power calculation:

$$
\text { Power }(\text { Watt })=\text { torque }(\mathrm{N} \cdot \mathrm{m}) \times 2 \pi \times N_{\mathrm{js}}(\mathrm{rps}) \text {. }
$$

2.3. Determining $S$ Values. $S$, the dimensionless geometric factor in Zwietering's equation, is calculated from Zwietering's equation below, upon the visual determination of $N_{\mathrm{js}}$. $S$ values agreeing with published data imply that the use of Zwietering's equation to predict $N_{\text {js }}$ for the given system 


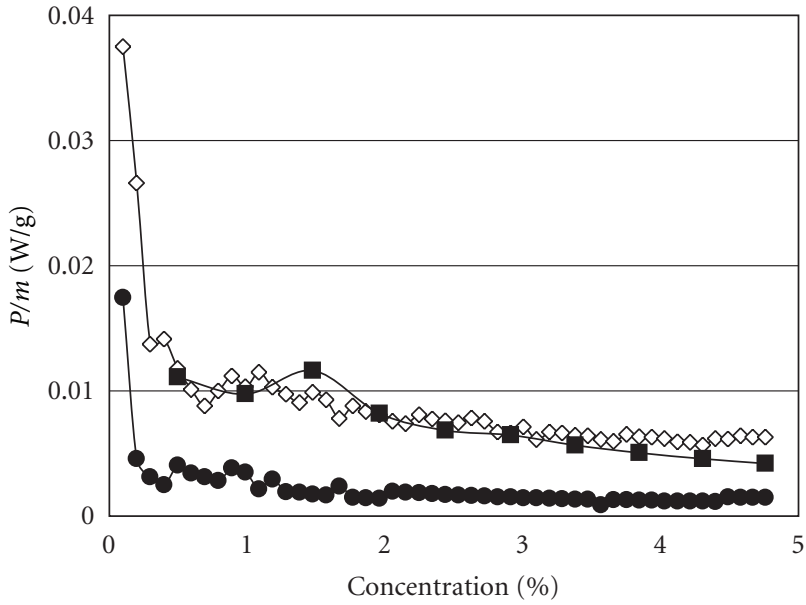

(a)

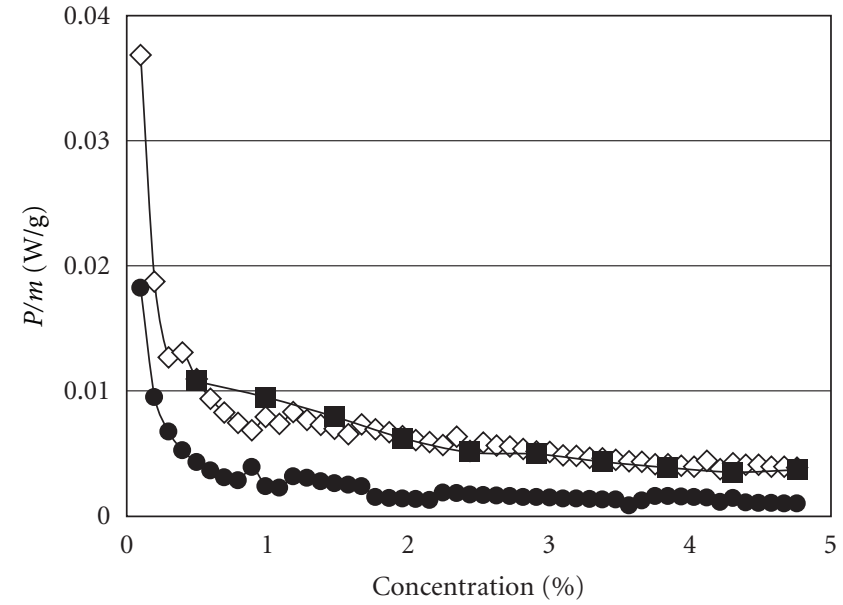

(b)

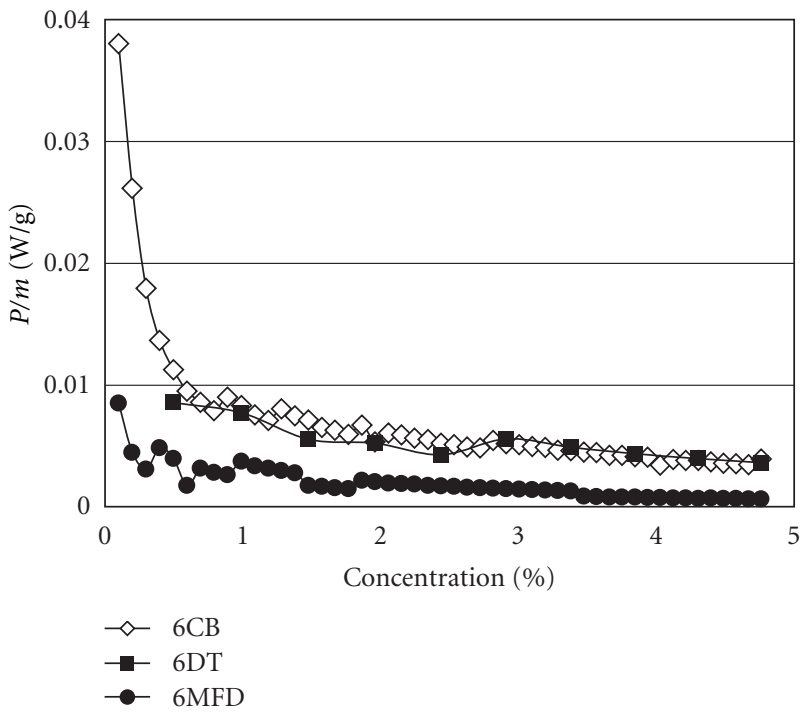

(c)

Figure 7: Power per unit solid mass (W/g) versus concentration (\%), at varying impeller geometries. (a) size of activated carbon 1.40$2.36 \mathrm{~mm}$, (b) size of activated carbon $1.00-1.40 \mathrm{~mm}$, and (c) size of activated carbon $0.75-1.00 \mathrm{~mm}$.

will produce values within the range obtained by visual observation:

$$
N_{\mathrm{js}}=\frac{S\left(g \Delta \rho / \rho_{L}\right)^{0.45}\left(d_{p}\right)^{0.2} X^{0.13} \gamma^{0.1}}{D^{0.85}} .
$$

\section{Results and Discussion}

3.1. Comparing Impeller Performance. Figures 5(a) to 5(c) show the minimum speeds for each impeller to achieve justsuspension over the range of PSAC concentrations. The plots in all cases show $N_{\mathrm{js}}$ increasing nearly proportionally to the particle concentration, with the slope of the curves reducing at a point between $1 \%$ to $2 \%$ concentration. The graphs also clearly show that higher speeds are required for the two radial impellers, the Rushton and curved blade compared to the downpumping mixed flow. To illustrate, at $1.0 \%$ concentration of activated carbon, $N_{\mathrm{js}}$ for $6 \mathrm{MFD}$ was $295 \mathrm{rpm}$, while for $6 \mathrm{CB}$ and $6 \mathrm{DT}$ were $430 \mathrm{rpm}$ and $410 \mathrm{rpm}$, respectively.

In relation to the speed requirement, Figures 6(a) to 6(c) show the 6MFD requiring less power than the radial $6 \mathrm{CB}$ and $6 \mathrm{DT}$ at the suspension points of each solid concentration, while the power for both the 6CB and 6DT are close to each other. The increase in power demand in going from 6MFD to the radial impellers can be from $100 \%$ to higher than $200 \%$. Hence, as reported in previous work, the mixed flow impeller achieves suspension at speeds and power inputs lower than the radial impellers [17]. The same trend is observed with the three size ranges of activated carbon particles.

Plots of specific power or power per unit mass versus concentration (Figures 7(a) to 7(c)) also show much lower values for the $6 \mathrm{MFD}$ compared to the radial impellers. This observation may be so because of the range of solids concentrations used here. In studies with slurries concentrations 


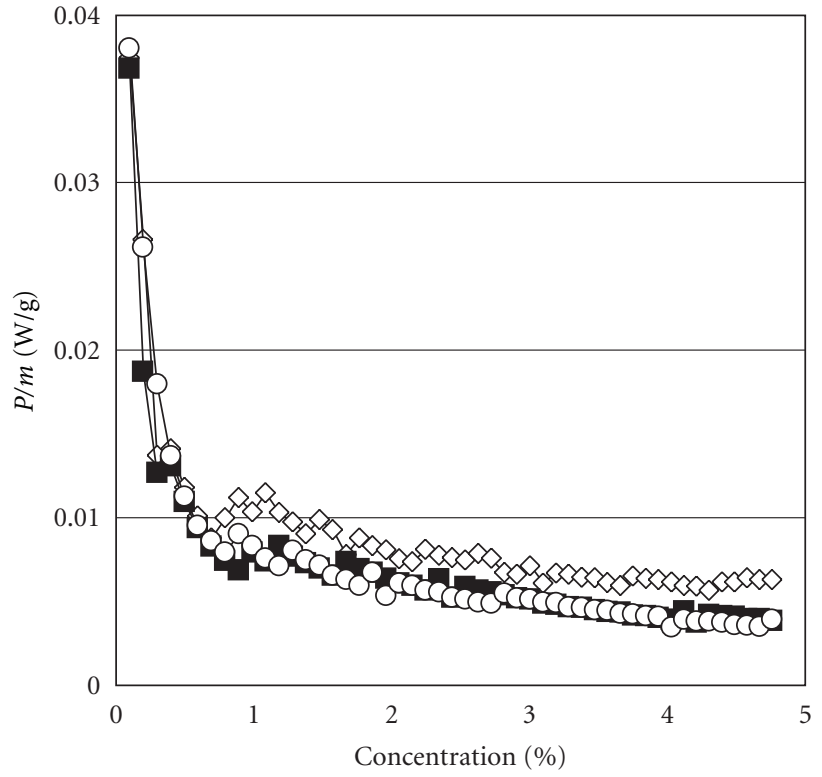

(a)

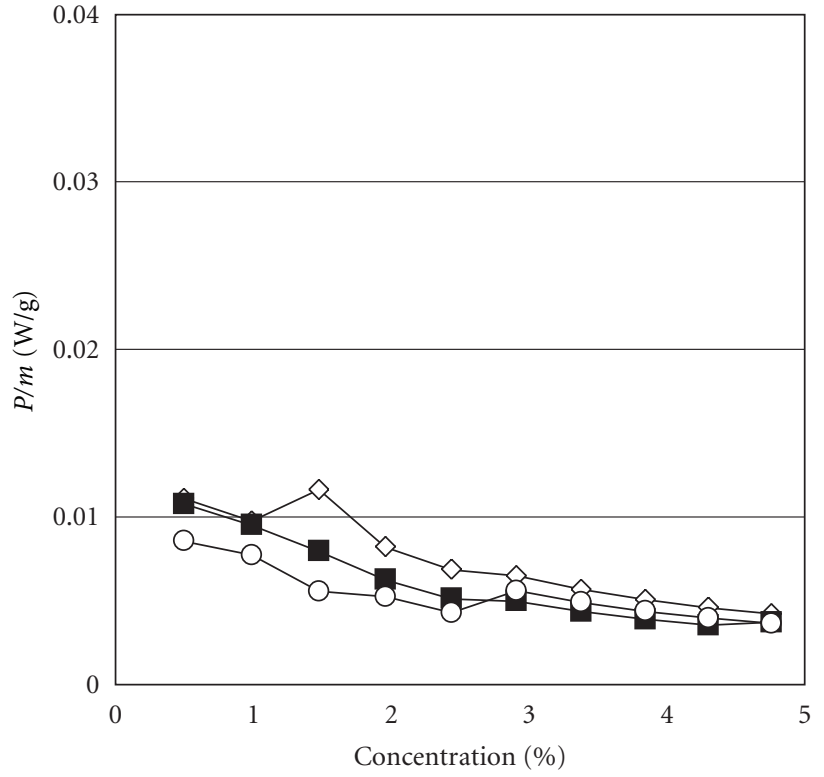

(b)

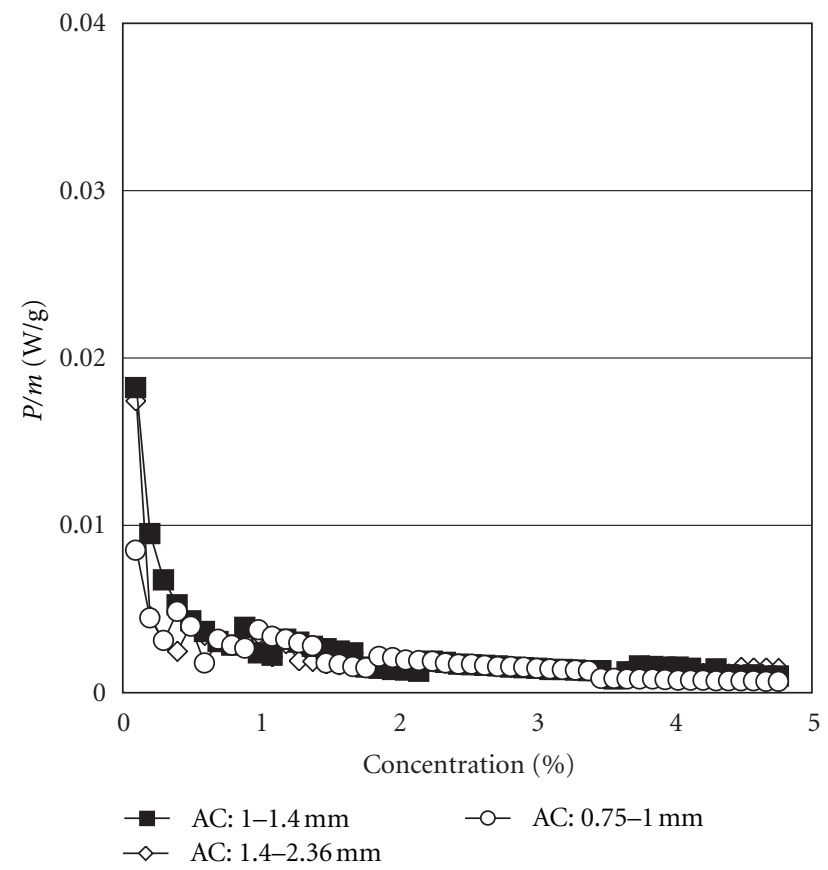

(c)

FIGURE 8: Power per unit solid mass (W/g) versus concentration (\%), at varying sizes of activated carbon. (a) 6CB impeller, (b) 6DT impeller, and (c) 6MFD impeller.

going as high as $50 \%$ by volume [23], the specific power for radial impellers was less than pitched-blade pumping axially downwards (similar to the 6MFD). Nevertheless, the plots in Figures 7(a) to 7 (c) do show the drop towards minima for all cases, and the differences between the radial and downpumping impellers getting less as the minima is approached. It is also interesting to note that since power per unit mass decreases with increase in particle concentration, it is in fact more efficient to perform the solid suspension operation in the stirred tank at higher particles concentration, until the specific power increases again after the minimum. Hence, there is an optimum concentration for slurry mixing [23]. Figures $8(\mathrm{a})$ to $8(\mathrm{c})$ show the effect of particle size to be less important especially for the 6MFD.

The impeller geometry causes particles to be distributed at certain regions on the base before suspension occurs. As reported earlier [17], for downward pumping 6MFD particles are divided in the centre and side as shown in Figure 9 with more being pushed to the side, since the impeller diameter is less than half the tank diameter [17]. As the speed 


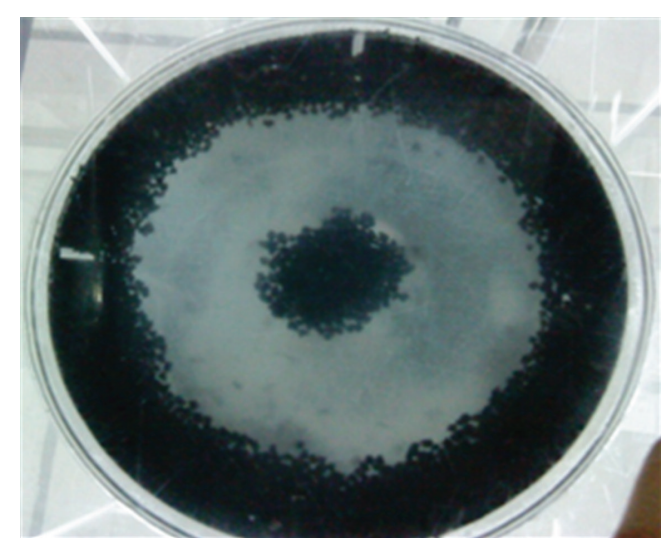

FIgure 9: Particle distribution by 6MFD.

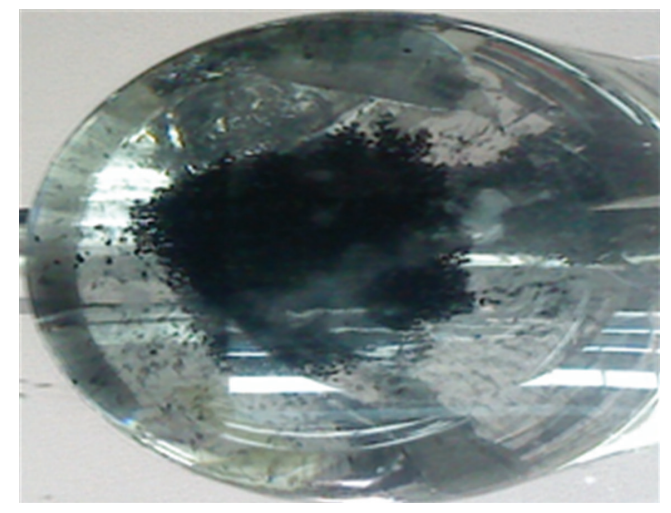

Figure 10: Particle distribution by 6CB.

of impeller increases, particles at the centre get suspended first followed by those around the side of the base. There was tendency for some of the particles to get stuck behind the baffles. The $6 \mathrm{DT}$ is known to have particles pulled to the centre for suspension, and the $6 \mathrm{CB}$ which is also a radial impeller has shown a similar distribution although the "star" shape of the 6DT is less distinct (Figures 10 and 11).

3.2. Effect of Particle Size. In Figure 12(a) for $6 \mathrm{CB}$ the $N_{\mathrm{js}}$ for the largest size range is greater than sizes below $1.4 \mathrm{~mm}$ beyond a concentration of about $1.8 \%$. With the lower two size ranges, not much difference in $N_{\mathrm{js}}$ values is observed between them. Data for the Rushton (Figure 12(b)) show a similar trend, but for the 6MFD (Figure 12(c)) the $N_{\mathrm{js}}$ values for different particle sizes, are quite similar, and the $N_{\text {js }}$ for particles larger than $1.40 \mathrm{~mm}$ increase only as particle concentration increased to about $3.2 \%$.

Figures 13(a) to 13(c) show the power consumption according to different particle sizes at different concentrations. In general the power increases with size and concentration. For the $6 \mathrm{CB}$ power for the largest size range is clearly higher than the lower two size range. The 6DT shows increase from one size range to another, while the 6MFD has less difference among the different sizes, with fluctuations in power as particle concentration increased.

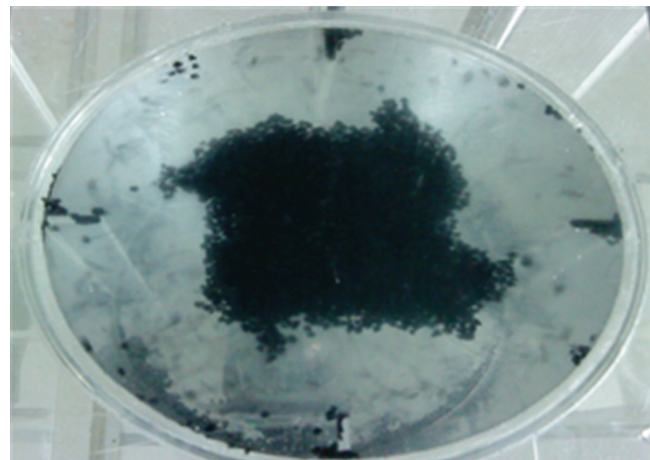

Figure 11: Particle distribution by 6DT.

Activated carbon with particle size $1.40-2.36 \mathrm{~mm}$ required higher speeds and power because being larger, they are also heavier than particles of the $1.00-1.40 \mathrm{~mm}$ and $0.75-$ $1.00 \mathrm{~mm}$ size range even though all the particles have the same density. This is so since the mass is related to the particle density and volume as follows:

$$
\text { Mass }=\text { Density } \times \text { Volume, }
$$

where assuming spherical shape for the particles, volume is directly dependent on particle size by the formula: $V=$ $\pi D^{2} / 4$. A larger volume means bigger mass and bigger weight as well, since weight $=$ mass $\times$ gravitational acceleration.

Hence, more energy is required to move larger particles from the bottom of vessel, and thus $N_{\text {is }}$ value increased.

Overall in this work, it is seen that in the lower size range, particle size does not have significant impact on the minimum suspension speed and power requirement, but with the larger size range from 1.40 to $2.36 \mathrm{~mm}$ the need for more energy is more significant and noticeable.

3.3. $S$ Values. $S$, the geometric factor in Zwietering's equation is to account for variation in the geometry of the impeller and tank. Available $S$ values are useful for the prediction of $N_{\mathrm{js}}$ using Zwietering's equation. In the plots against concentration (Figures 14(a)-14(c)), the $S$ values stabilize to nearly constant after $1 \%$ particles concentration. The average values are given in Table 2(a). The 6CB has $S$ values close to the 6DT since both have similar $N_{\mathrm{js}}$ readings. Compared to $S$ from previous work [17] given in Table 2(b), the 6MFD $S$ values are close to the earlier reported values, while that for 6DT tend to be lower in this work. This could be due to the differences in experimental condition such as particle size and concentration, and the subjective nature of the visual technique. Nevertheless, the results indicate that Zwietering's equation can be used to reasonably predict the minimum just-suspension speed for porous particles as used here, with the density adjusted to incorporate the submerged void space. If the solid density alone is used as it is in Zwietering's equation, the $S$ values would be $28.5 \%$ lower than the values obtained here, making even greater difference from published data. In Figures 15(a) to 15(c), $S$ seems to be affected by the particle size as shown by the 6MFD as well as 


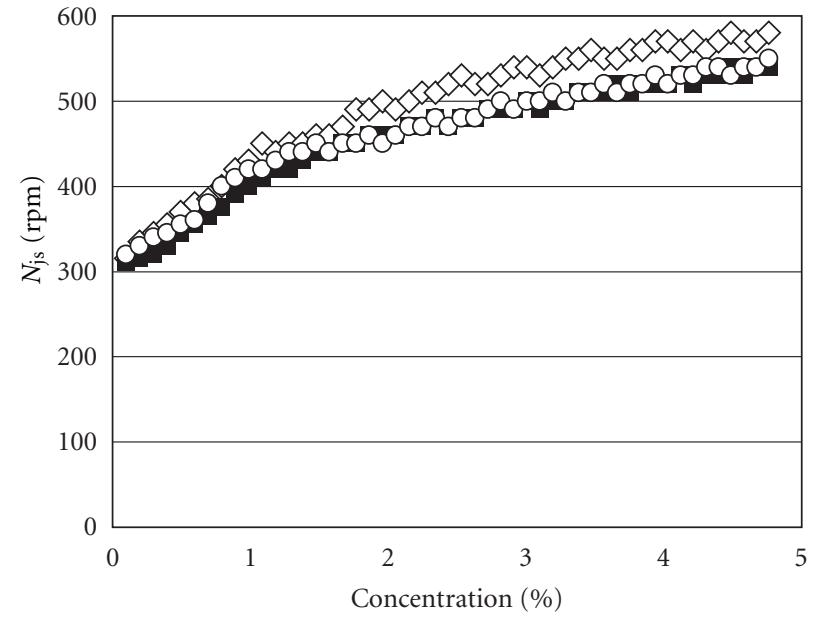

(a)

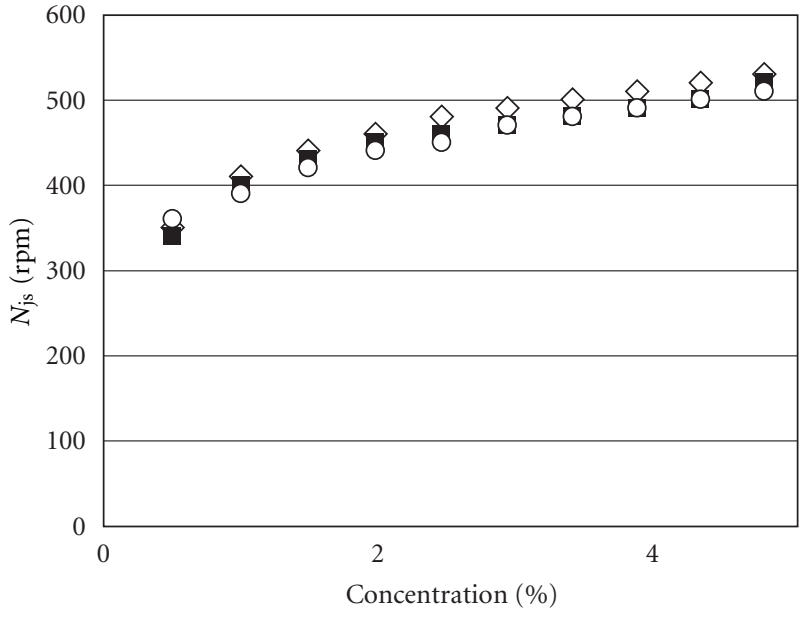

(b)

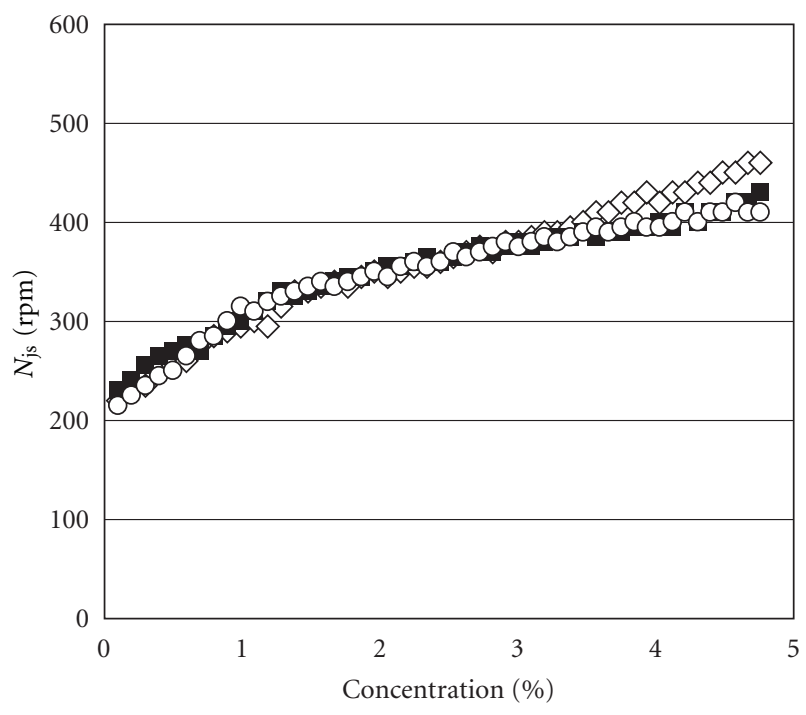

$\diamond$ AC: $1.4-2.36 \mathrm{~mm}$

- AC: $1-1.4 \mathrm{~mm}$

O AC: $0.75-1 \mathrm{~mm}$

(c)

FIGURE 12: Graph $N_{\text {js }}(\mathrm{rpm})$ versus concentration (\%), at varying sizes of activated carbon. (a) 6CB impeller, (b) 6DT impeller, and (c) 6MFD impeller.

6DT impellers. For the 6CB the $S$ values for the smallest size range are distinctly higher than the other two size ranges.

\section{Conclusion and Recommendations}

In this study, the suspension of porous activated carbon particles has been observed using 6-blade impellers of three geometries-downward pumping mixed-flow, Rushton disc turbine and curved blade. The first objective is to evaluate the performance of the curved blade turbine as compared to the 6DT and 6MFD, which has often been reported. The second objective is to evaluate the use of Zwietering's equation for
$N_{\text {is }}$ prediction with particles of high porosity, since such particles have a high percentage of void volume that is filled with liquid when they are submerged thus altering the actual density of the particles to be suspended.

As established in the literature for solids concentration lower than 20\%, the mixed-flow 6MFD showed significantly greater efficiency for particle suspension compared to the two radial impellers $6 \mathrm{CB}$ and $6 \mathrm{DT}$, both with respect to minimum speed for suspension and power requirement. But in terms of specific power the differences reduce as the plots tend towards minima with increase in concentration, indicating that the trend may shift to the radial being better at higher concentrations as already reported by other workers 


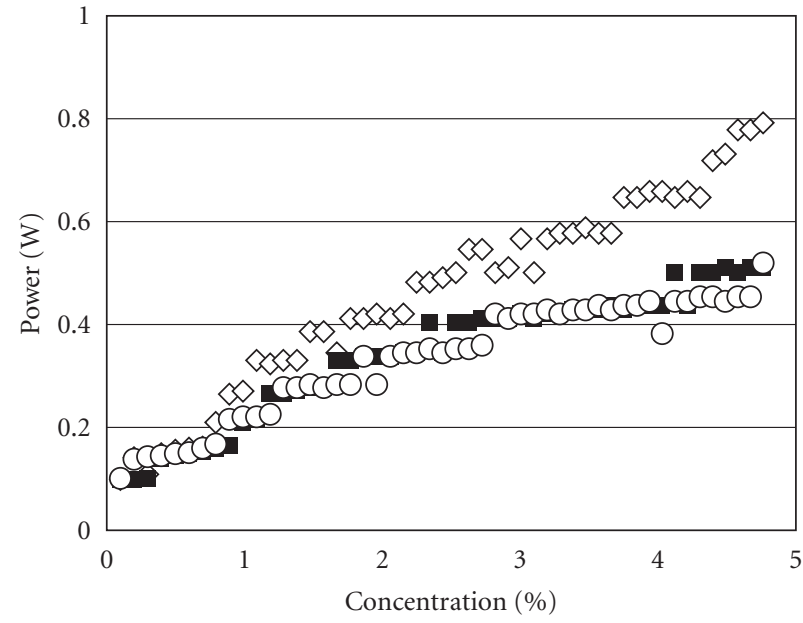

(a)

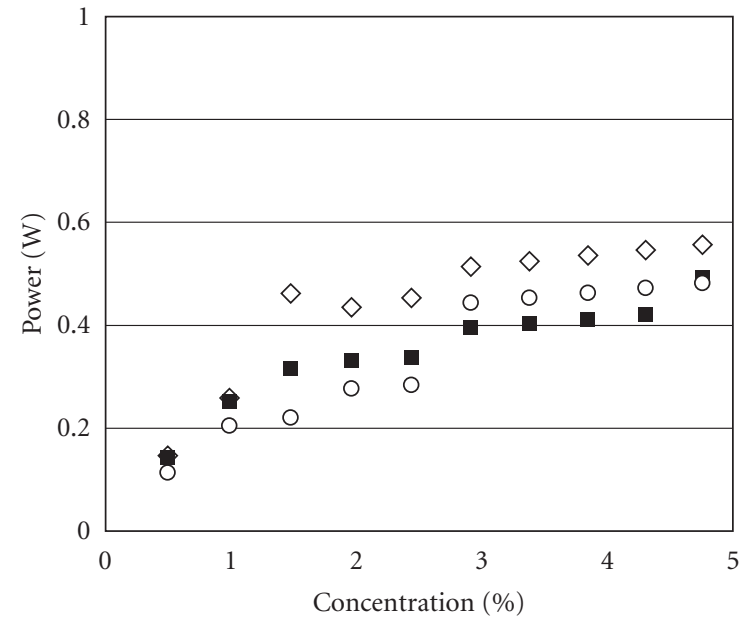

(b)

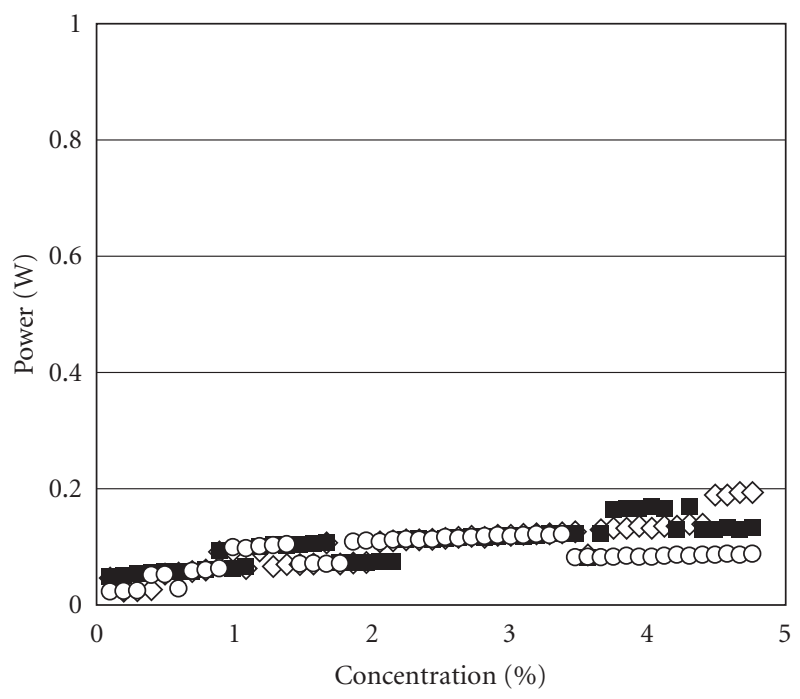

$\diamond$ AC: $1.4-2.36 \mathrm{~mm}$

- AC: $1-1.4 \mathrm{~mm}$

O AC: $0.75-1 \mathrm{~mm}$

(c)

FIGURE 13: Graph power (watt) versus concentration (\%), at varying sizes of activated carbon. (a) 6CB impeller, (b) 6DT impeller, and (c) 6MFD impeller.

[23]. Interestingly, both the radial impellers, the 6DT and 6CB, show similar $N_{\mathrm{js}}$ and power values under the same conditions. The points of last suspension are as reported [17], where with the 6MFD particles move out from the centre to the side, while for the radial impellers, particle are moved to the centre to be suspended.

Activated carbon with sizes $1.40-2.36 \mathrm{~mm}$ required higher speeds and power to reach just-suspension compared to particles of $1.00-1.40 \mathrm{~mm}$ and $0.75-1.00 \mathrm{~mm}$ size range. The latter two size ranges show close suspension speeds requirement.

$S$ values have been obtained for the curved blade impeller. As expected since the $N_{\mathrm{js}}$ for $6 \mathrm{CB}$ is close to $6 \mathrm{DT}$, the $S$ values are also similar. The $S$ values obtained for 6MFD are lower compared to $6 \mathrm{CB}$ and $6 \mathrm{DT}$ but agree with previous reports.

\section{Nomenclature}

$N_{\mathrm{js}}$ : Minimum speed to achieve just-suspension (rps)

$d_{p}$ : Particle size $(\mathrm{m})$

$X: \quad$ wt. solids/wt. liquid $\times 100(\%)$

$D$ : Impeller diameter $(\mathrm{m})$

C: Off-bottom clearance (m)

T: Tank diameter $(\mathrm{m})$

$H$ : Mixing height (m) 


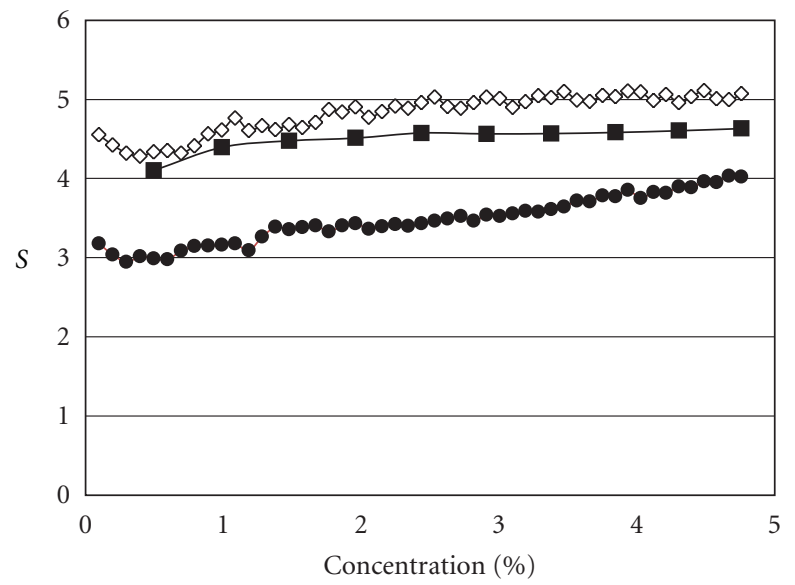

(a)

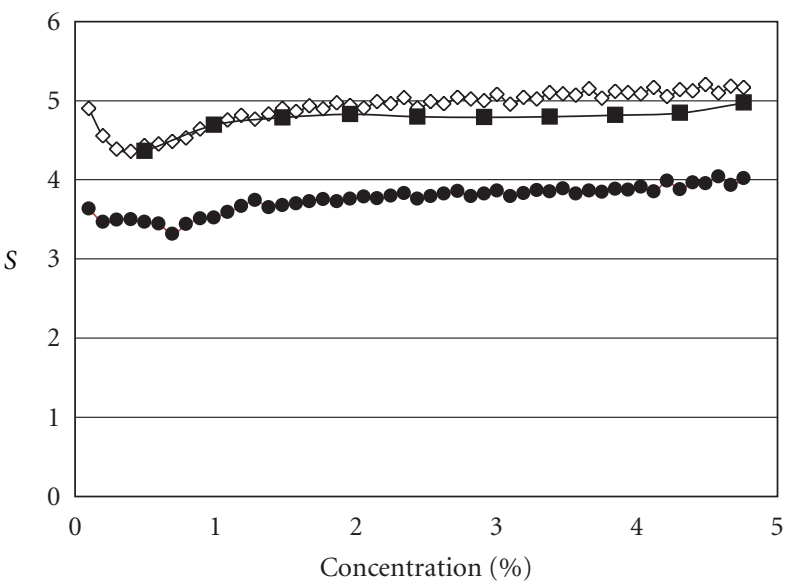

(b)

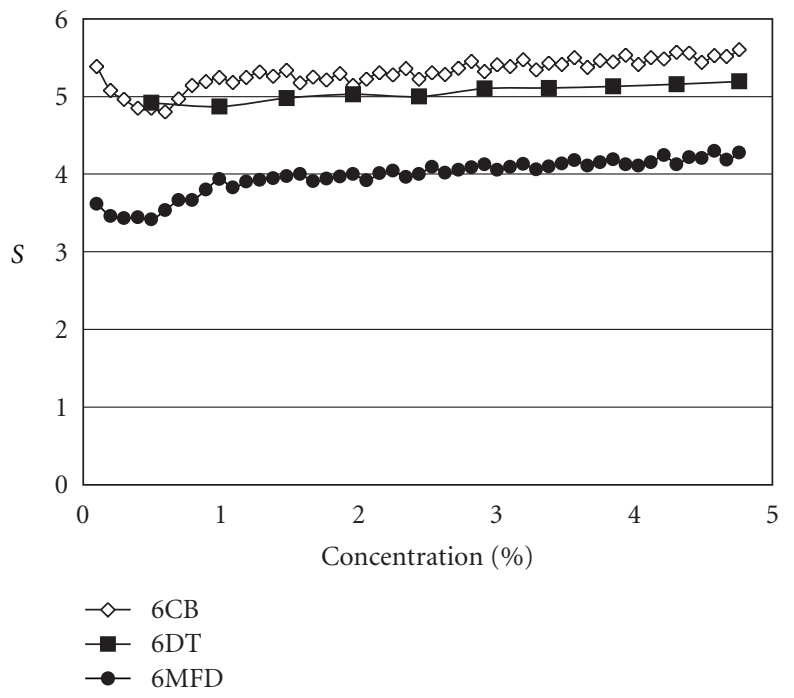

(c)

FIGURE 14: $S$ values versus concentration (\%), at varying impeller geometries. (a) size of activated carbon 1.40-2.36 mm, (b) size of activated carbon 1.00-1.40 mm, and (c) size of activated carbon $0.75-1.00 \mathrm{~mm}$.

TABLE 2

(a) Average $S$ values (present work)

\begin{tabular}{lccc}
\hline & & $S$ & \\
Impeller & $1.40-2.36 \mathrm{~mm}$ & $1.00-1.40 \mathrm{~mm}$ & $0.75-1.00 \mathrm{~mm}$ \\
\hline $6 \mathrm{CB}$ & 4.82 & 4.91 & 5.31 \\
$6 \mathrm{DT}$ & 4.50 & 4.77 & 5.05 \\
$6 \mathrm{MFD}$ & 3.48 & 3.75 & 3.98 \\
\hline
\end{tabular}

(b) The literature $S$ values [17]

\begin{tabular}{lcccc}
\hline & & & & \\
Impeller & $D / T$ & $C / T$ & $\operatorname{BLGB}\left(d_{p}=0.6-0.71 \mathrm{~mm}\right)$ & Bronze shot $\left(d_{p}=0.5-0.6 \mathrm{~mm}\right)$ \\
\hline \multirow{2}{*}{ 6DT } & & 0.17 & 5.12 & 5.72 \\
& 0.33 & 0.25 & 7.33 & 6.58 \\
\multirow{2}{*}{ 6MFD } & & 0.33 & 8.37 & \\
& 0.33 & 0.25 & 3.94 & 4.03 \\
\hline
\end{tabular}




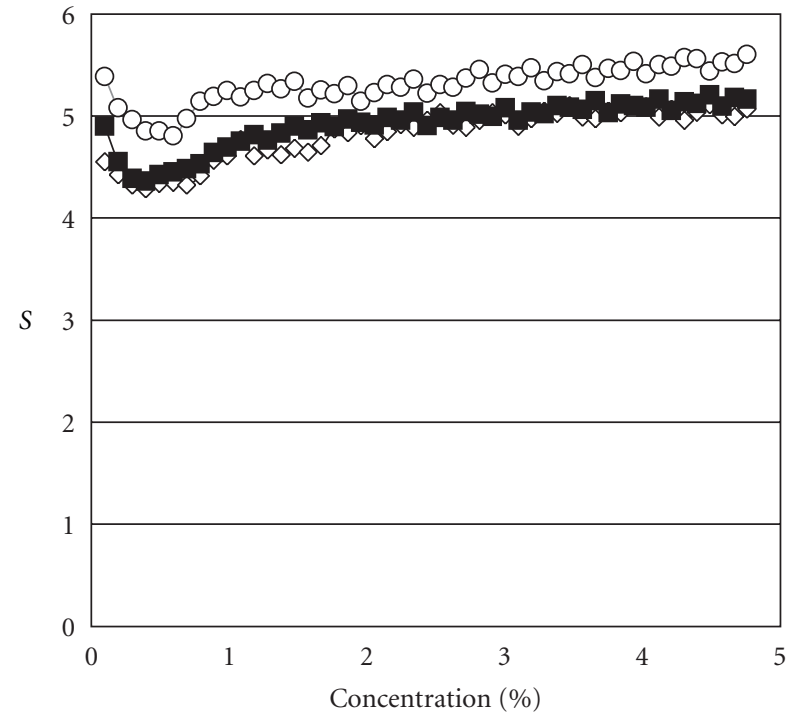

(a)

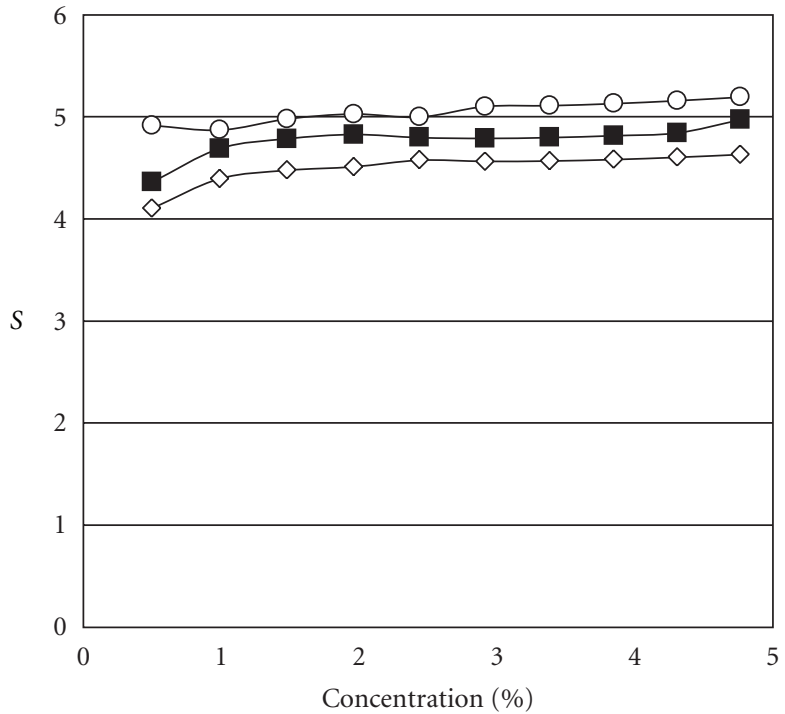

(b)

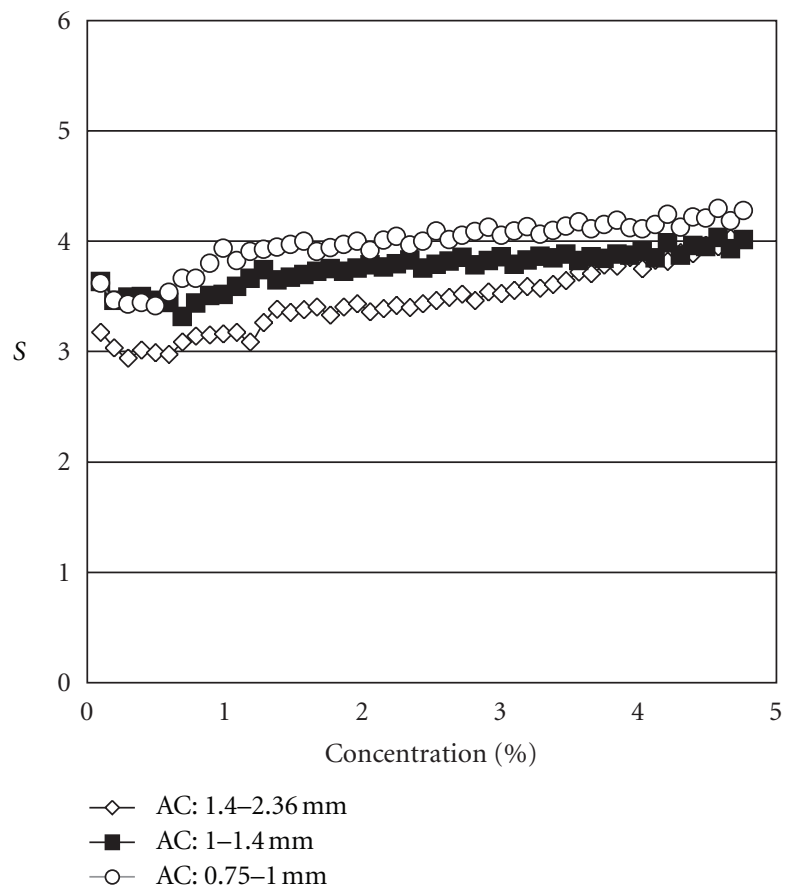

(c)

Figure 15: $S$ values versus concentration (\%), at varying sizes of activated carbon. (a) 6CB impeller, (b) 6DT impeller, and (c) 6MFD impeller.

$V:$ Volume $\left(\mathrm{m}^{3}\right)$

g: Gravitational constant $\left(\mathrm{ms}^{-2}\right)$

$S$ : Dimensionless geometricfactor (-).

\section{Greek Letters}

$\Delta \rho: \quad \rho_{s, \text { eff }}-\rho_{L}$, density difference $\left(\mathrm{kg} \mathrm{m}^{-3}\right)$

$\rho_{L}$ : Fluid density $\left(\mathrm{kg} \mathrm{m}^{-3}\right)$

$\rho_{s, \text { eff: }}$ Effective solid density $\left(\mathrm{kg} \mathrm{m}^{-3}\right)$ $\rho_{s}$ : Solid density $\left(\mathrm{kg} \mathrm{m}^{-3}\right)$

$\nu$ : Kinematic viscosity $\left(\mathrm{m}^{2} \mathrm{~s}^{-1}\right)$.

\section{Acknowledgment}

The authors would like to acknowledge the Fundamental Research Grant Scheme (FRGS) awarded by the Ministry of Higher Education, Malaysia, for making this study possible. 


\section{References}

[1] V. Kolar, "Studies on mixing X: suspending solids particles in liquids by means of mechanical agitation," Collection of Czechoslovak Chemical Communications, vol. 26, pp. 613-627, 1961.

[2] K. T. K. Shimizua, K. Takahashi, E. Suzukia, and T. Nomura, "Effect of baffle geometries on crystal size distribution of aluminum potassium sulfate in a seeded batch crystallizer," Journal of Crystal Growth, vol. 197, no. 4, pp. 921-926, 1999.

[3] J. Wu, L. Graham, S. Wang, and R. Parthasarathy, "Energy efficient slurry holding and transport," Minerals Engineering, vol. 23, no. 9, pp. 705-712, 2010.

[4] D. Chapple, S. M. Kresta, A. Wall, and A. Afacan, "The effect of impeller and tank geometry on power number for a pitched blade turbine," Chemical Engineering Research and Design, vol. 80, no. 4, pp. 364-372, 2002.

[5] M. Greaves and Y. Y. Loh, "Power consumption effect in three phase mixing," ICHEME Symposium Series, vol. 89, pp. 69-96, 1984.

[6] A. W. Nienow, M. Konno, and W. Bujalski, "Studies on threephase mixing: a review and recent results," Chemical Engineering Research and Design, vol. 64, no. 1, pp. 35-42, 1986.

[7] C. M. Chapman, A. W. Nienow, M. Cooke, and J. C. Middleton, "Particle-gas-liquid mixing in stirred vessels part III: three phase mixing," Chemical Engineering Research and Design, vol. 61, no. 3, pp. 167-181, 1983.

[8] N. Dohi, T. Takahashi, K. Minekawa, and Y. Kawase, "Power consumption and solid suspension performance of large-scale impellers in gas-liquid-solid three-phase stirred tank reactors," Chemical Engineering Journal, vol. 97, no. 2-3, pp. 103-114, 2004.

[9] S. Ibrahim and A. W. Nienow, "The effect of viscosity on particle suspension in an aerated stirred vessel with different impellers and bases," Chemical Engineering Communications, vol. 197, no. 4, pp. 434-454, 2010.

[10] A. Brucato, A. Cipollina, G. Micale, F. Scargiali, and A. Tamburini, "Particle suspension in top-covered unbaffled tanks," Chemical Engineering Science, vol. 65, no. 10, pp. 3001-3008, 2010.

[11] G. Baldi, R. Conti, and E. Alaria, "Complete suspension of particles in mechanically agitated vessels," Chemical Engineering Science, vol. 33, no. 1, pp. 21-25, 1978.

[12] M. W. Chudacek, "Relationships between solids suspension criteria, mechanism of suspension, tank geometry, and scaleup parameters in stirred tanks," Industrial and Engineering Chemistry Fundamentals, vol. 25, no. 3, pp. 391-401, 1986.

[13] M. W. Chudacek, "Solids suspension behaviour in profiled bottom and flat bottom mixing tanks," Chemical Engineering Science, vol. 40, no. 3, pp. 385-392, 1985.

[14] R. Conti, S. Sicardi, and V. Specchia, "Effect of the stirrer clearance on particle suspension in agitated vessels," Chemical Engineering Journal, vol. 22, no. 3, pp. 247-249, 1981.

[15] F. Rieger, "Effect of particle content on agitator speed for offbottom suspension," Chemical Engineering Journal, vol. 79, no. 2, pp. 171-175, 2000.

[16] D. J. Gray, "Impeller clearance effect on off-bottom particle suspension in agitated vessels," Chemical Engineering Communications, vol. 61, pp. 152-158, 1987.

[17] S. Ibrahim and A. W. Nienow, "Particle suspension in the turbulent regime: the effect of impeller type and impeller/vessel configuration," Trans IChemE, vol. 74, no. 6, pp. 679-688, 1996.
[18] S. Ibrahim and A. W. Nienow, "Suspension of microcarriers for cell culture with axial flow impellers," Transactions of the Institutions of Chemical Engineers A, vol. 82, no. 9, pp. 10821088, 2004.

[19] S. Ibrahim and A. W. Nienow, "Comparing impeller performance for solid-suspension in the transitional flow regime with Newtonian fluids," Chemical Engineering Research and Design, vol. 77, no. 8, pp. 721-727, 1999.

[20] J. Wu, Y. Zhu, and L. Pullum, "Impeller geometry effect on velocity and solids suspension," Chemical Engineering Research and Design, vol. 79, no. 8, pp. 989-997, 2001.

[21] P. M. Armenante and E. U. Nagamine, "Effect of low offbottom impeller clearance on the minimum agitation speed for complete suspension of solids in stirred tanks," Chemical Engineering Science, vol. 53, no. 9, pp. 1757-1775, 1998.

[22] T. N. Zwietering, "Suspending of solid particles in liquid by agitators," Chemical Engineering Science, vol. 8, no. 3-4, pp. 244-253, 1958.

[23] J. Wu, Y. G. Zhu, and L. Pullum, "Suspension of high concentration slurry," AIChE Journal, vol. 48, no. 6, pp. 1349-1352, 2002. 

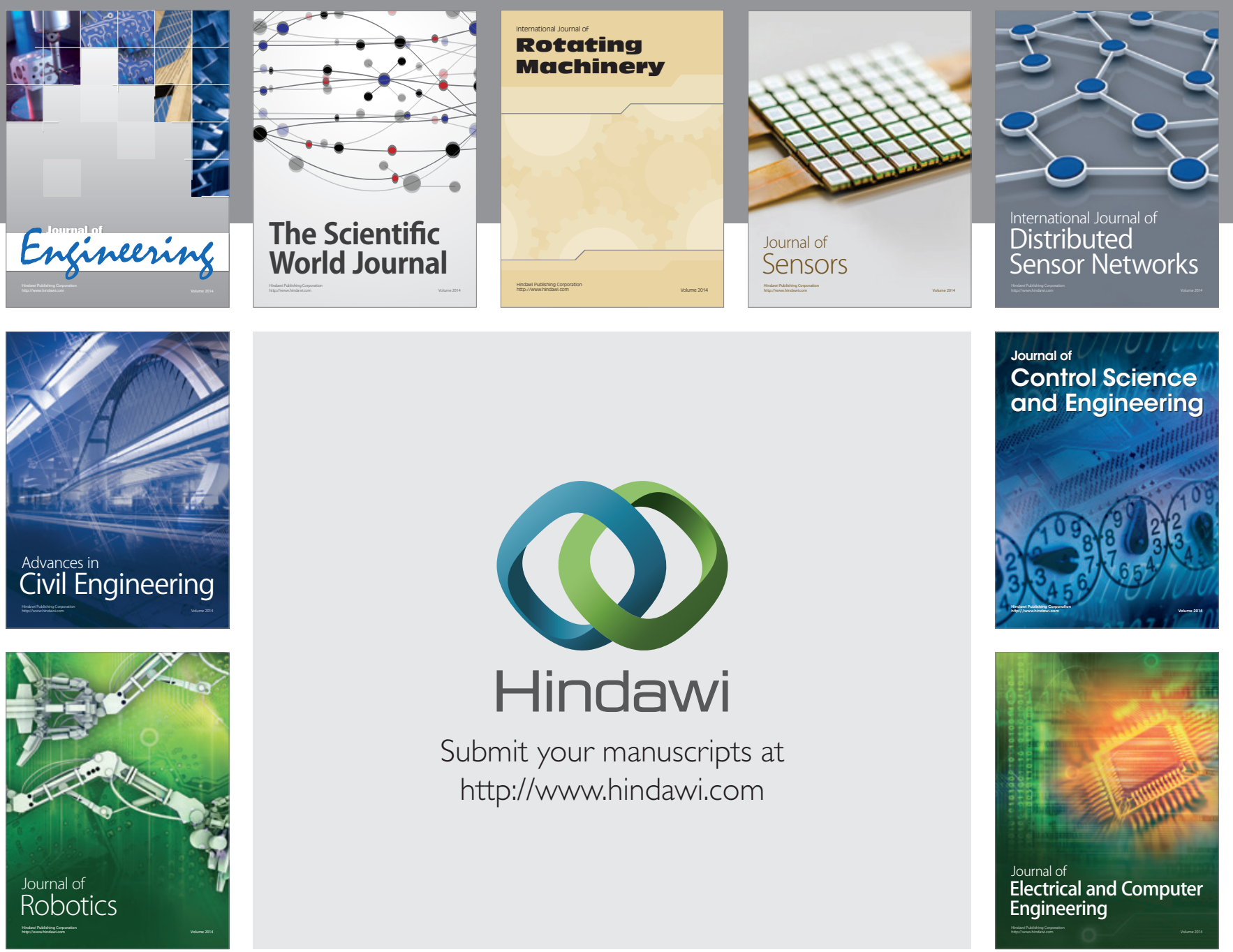

Submit your manuscripts at

http://www.hindawi.com
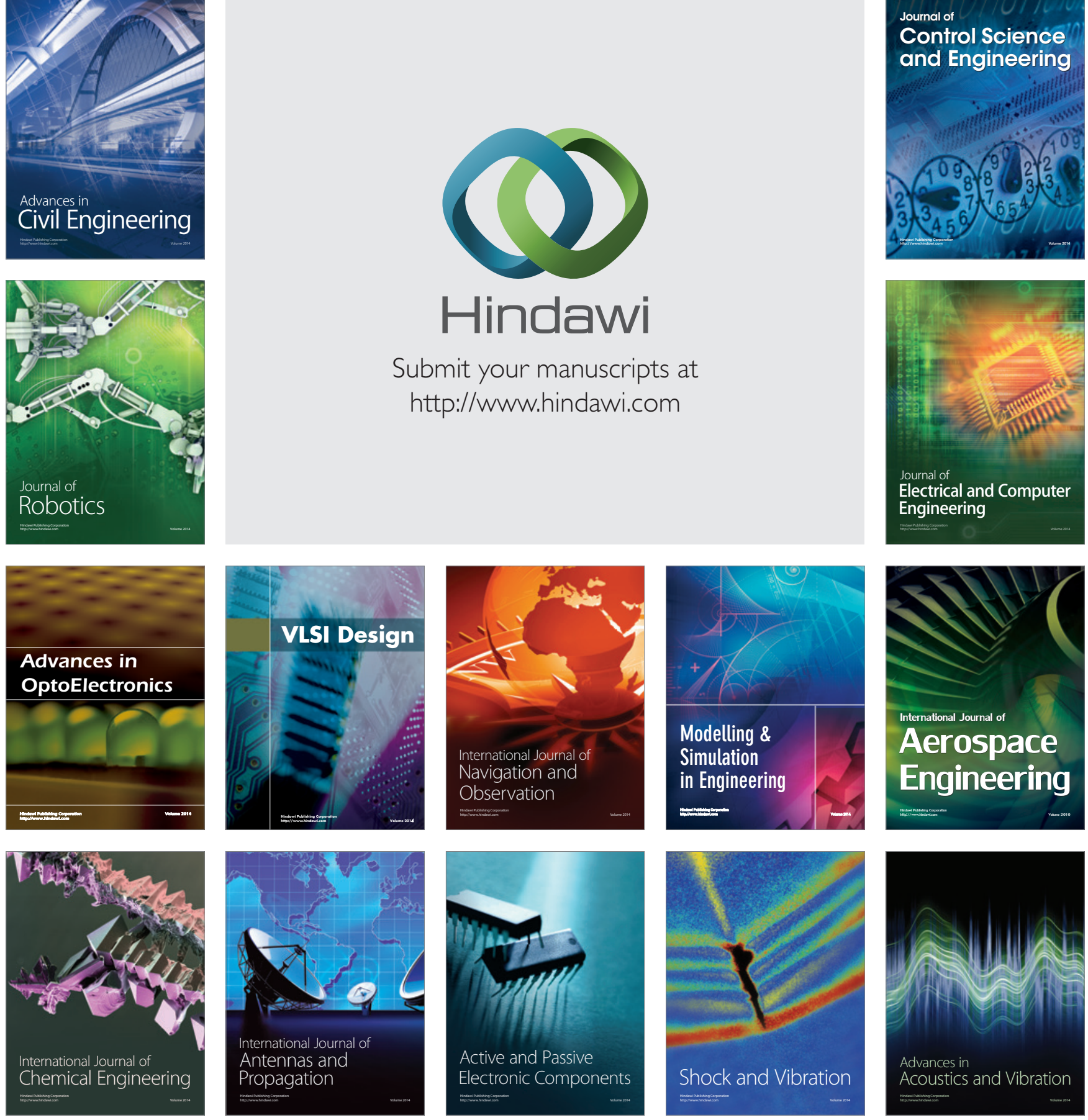